\title{
Um balanço das políticas do governo Lula para a educação superior: continuidade e ruptura
}

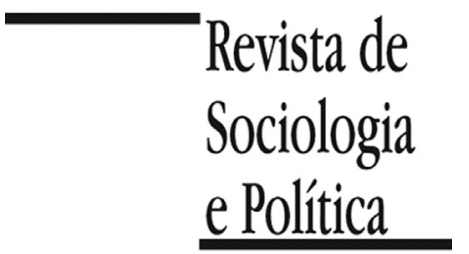

DOI 10.1590/1678-987316245708

\section{Vilma Aguiar}

\begin{abstract}
Resumo
O trabalho apresenta e analisa as principais políticas para o setor privado de educação superior adotadas pelo governo de Luiz Inácio Lula da Silva (2003/2010). A partir de uma retrospectiva histórica e de uma análise de sua implementação, as políticas são consideradas por meio de uma revisão crítica da literatura e dos dados oficiais. O trabalho demonstra que, apesar de ter realizado políticas para o setor público bastante distintas das do governo de Fernando Henrique Cardoso, no caso do setor privado, há antes um aprofundamento das opções políticas já desenvolvidas durante o governo de Cardoso. Essas opções se traduzem em ações de fomento ao desenvolvimento do setor privado, na medida em que ampliaram o financiamento deste e consolidaram um marco legal que proporcionou segurança jurídica às mantenedoras. Esse fomento, entretanto, veio acompanhado de um sensível aumento e aperfeiçoamento dos mecanismos de controle sobre o crescimento do setor privado.
\end{abstract}

PALAVRAS-CHAVE: setor privado de educação superior; reforma univeristária; educação superior; políticas públicas; governo Lula.

Recebido em 16 de Novembro de 2014. Aceito em 12 de Março de 2015.

\section{Introdução ${ }^{1}$}

${ }^{1}$ Agradeço aos pareceristas anônimos da Revista de Sociologia e Política por seus comentários.
A s principais balizas do debate contemporâneo sobre educação superior podem ser resumidas em grandes questões expressas na literatura em pares conceituais como acesso e equidade; qualidade e massificação; privatização e mercantilização; diversidade e diferenciação (cf. Silva Junior \& Sguissardi 2005; Dias Sobrinho 2010; Morosini 2009). Essas questões foram trazidas principalmente por uma grande expansão mundial, ocorrida a partir de 1970. Segundo Sampaio (2014), entre 1975-1995 as matrículas dobraram, passando de 40 para 80 milhões. Em 2000, já havia 100 milhões estudantes universitários. Um século antes, estes não eram mais que 500 mil.

No Brasil, o início da grande expansão ocorreu a partir de 1995, no governo de Fernando Henrique Cardoso (1995-2003) e esta prosseguiu, a taxas um pouco decrescentes, durante o governo de Luiz Inácio Lula da Silva (20042010). No período, as matrículas passaram de cerca de um milhão e setecentos mil, em 1995, a seis milhões e trezentos mil em 2010. Nesse sentido, a onda brasileira se inscreveu em um movimento internacional, mas precisou lidar com as particularidades do sistema já implantado aqui e com as demandas econômicas e sociais oriundas de um represamento enfim desatado do crescimento da economia brasileira e do acirramento das disputas em torno da necessidade de mitigação das desigualdades raciais, econômicas, de gênero etc. No final dos anos 1990, em linhas bastante gerais, esse sistema pôde ser descrito como (i) bastante elitista em termos de possibilidade de acesso; (ii) dual, no sentido de que os setores público e privado desempenham papeis complementares; (iii) constituído por uma larga predominância do setor privado; (iv) concentrado em poucas carreiras; e (v) pouco interiorizado e enraizado (Sampaio 2000; Aguiar 2013). 
2 "Privatização refere-se ao avanço da participação do setor privado no total de matrículas e de instituições de ensino superior; já o termo mercantilização remete à emergência de instituições com fins lucrativos no país os novos provedores, conforme a denominação de Brunner e Uribe (2007) - e, em decorrência disso, às transações de aquisição que as envolvem e suas implicações no desenho do sistema nacional de ensino superior" (Sampaio 2014, p. 7).
Assim, ler as políticas públicas adotadas pelo governo Lula apenas como respostas à necessidade de gerar igualdade de oportunidades e inclusão social (Pereira \& Silva 2010) parece reducionista justamente porque aquelas dialogam com um conjunto mais amplo de questões, ou seja, outros pares conceituais já aludidos também têm de entrar nas equações explicativas a respeito das mudanças no sistema. Se, de um lado, programas como o PROUNI e o Fies abordam o problema da inclusão econômica de estudantes carentes, por outro, o aperfeiçoamento dos mecanismos de avaliação, levado a cabo com o SINAES, e o projeto de reforma universitária, debruçam-se sobre questões como a qualidade e a necessidade da diversidade e diferenciação do sistema. Além dos problemas de fundo, ou seja, a necessidade de regular a expansão e o peso do setor privado no conjunto do sistema.

Dessa forma, o viés da leitura aqui apresentada, privilegiando as medidas que se dirigem ao setor privado de educação superior, na avaliação das políticas adotadas pelo governo Lula, busca examinar como este lidou com as grandes questões políticas e sociais da educação superior. A hipótese é que, embora o governo tenha enfrentado os principais temas do debate e procurado se diferenciar do governo anterior, os resultados nas duas principais frentes são controversos. No lado da ampliação do acesso e da equidade, programas com o ProUni e o FIES trouxeram avanços pontuais. Entretanto, no par privatização/mercantilização ${ }^{2}$, estas se aprofundaram durante o governo Lula.

Do ponto de vista conceitual, o presente artigo se caracteriza como um estudo de políticas públicas. A intenção não é fazer uma discussão teórica sobre políticas públicas, mas estudar um objeto específico à luz dessa discussão. Do ponto de vista conceitual, considera-se algumas das definições mais consagradas pelo debate. Assim, segue-se a síntese sugerida por Souza (2006, p. 26), cuja ênfase recai sobre aspectos comuns sublinhados por diferentes autores quanto à centralidade das decisões e ações governamentais. É neste sentido que Lynn e Peters, por exemplo, convergem no que diz respeito aos efeitos específicos almejados e que influenciam a vida dos cidadãos, assim como Dye aponta para as escolhas das ações governamentais e Laswell para quem ganha e o que ganha com estas (apud Souza 2006).

Segundo Viana (1996), as diferentes abordagens teóricas das políticas públicas tentam explicar as interações e contradições entre as intenções, presentes durante a fase de formulação destas, e as ações, realizadas na fase de implementação (idem, p. 6). A distância, portanto, entre o que é pensando do que é efetivamente realizado. Além disso, pretendem dar conta das interações entre "o meio social, político e econômico e o governo (ou melhor, a ação governamental)", ou seja, "a relação que se estabelece entre atores governamentais e entre atores governamentais e não-governamentais no processo de 'fazer' política'" (ibidem).

Nesses termos, o problema abordado aqui diz respeito à maneira como o governo Lula atuou sobre os problemas históricos da educação superior brasileira, considerando também a maneira como os diferentes atores sociais envolvidos responderam a essa atuação.

\section{O Ensino Superior no governo Lula}

Apesar de haver um certo consenso no PT sobre quais seriam os problemas da educação superior e da abrangência das propostas apresentadas no plano de governo, as primeiras iniciativas do governo Lula para a educação foram tão ziguezagueantes quanto as mudanças no ministério. O primeiro ministro nomeado, Cristovam Buarque (2003), manteve-se pouco mais de um ano no cargo e não foi capaz de imprimir uma direção para as políticas educacionais, tendo 
sido substituído por Tarso Genro (2004-2005) em 27 de janeiro de 2004. Entretanto, durante a chamada crise do mensalão, este foi chamado para presidir o Partido dos Trabalhadores e foi substituído por Fernando Haddad (20052010), então secretário executivo do MEC, em 29 de julho de 2005. Fernando Haddad ficou no Ministério da Educação até o final do governo Lula e definiu o perfil das políticas efetivamente adotadas por este.

A impressão generalizada de uma gestão errática e sem projeto pode ser corroborada pela instituição, por iniciativa da Casa Civil, em outubro de 2003, por meio de um decreto presidencial, de um grupo de trabalho interministerial encarregado de analisar a situação das IFES (Instituições Federais de Educação Superior) e apresentar um plano de ação visando à reestruturação, desenvolvimento e democratização destas. A principal atribuição era propor medidas para enfrentar rapidamente a crise então vivida pelas universidades públicas, cujas verbas de custeio teriam diminuído cerca de 50\% durante o governo FHC, segundo afirmação do relatório final do GTI. Este, intitulado Bases para o enfrentamento da crise emergencial das universidades federais e roteiro para a Reforma Universitária brasileira é composto de quatro partes: ações emergenciais, autonomia universitária, complementação de recursos (financiamento) e as etapas para a implementação da Reforma Universitária. O texto do relatório, depois de afirmar que a década anterior foi de "desarticulação do setor público brasileiro", e que isso redundara em um quadro geral de crise para as universidades brasileiras, apresenta um diagnóstico genérico:

\begin{abstract}
"De um lado, as universidades governamentais sofreram consequências da crise fiscal do Estado que incidem sobre seus recursos humanos, de manutenção e de investimento. De outro lado, a prioridade ao setor privado em todas as áreas também chegou ao setor do Ensino Superior: as universidades privadas, que viveram uma expansão recorde nos últimos anos, chegando a responder, em 2002 , por $63,5 \%$ do total de cursos de graduação e $70 \%$ das matrículas, encontram-se agora ameaçadas pelo risco de uma inadimplência generalizada do alunado e de uma crescente desconfiança em relação a seus diplomas" (Brasil 2003).
\end{abstract}

A partir desse diagnóstico, o documento analisa rapidamente os números de matrículas e de docentes atuando no setor público, para apresentar a meta de dobrar a oferta de vagas em universidades públicas federais entre 2003 e 2007 , passando de 600 mil para um milhão e $200 \mathrm{mil}^{3}$. Apesar de algumas propostas pontuais e projeções quanto a custos e investimentos envolvidos nestas, a maior parte jamais colocada em prática, podemos afirmar que o documento apresentado, em seu conjunto, ficou muito aquém de um plano de ação que visaria à reestruturação, desenvolvimento e democratização das IFES. Ele é demasiadamente genérico, impreciso e irrealista ${ }^{4}$. Pensando nas etapas da reforma universitária, por exemplo, afirma que esta deve ser aprovada ainda em 2004 e colocada em prática já em $2005^{5}$. Ou seja, um ano depois da posse de Lula, o documento produzido por um conjunto representativo de ministérios ainda se assemelha a um documento de campanha.

Em fins de janeiro de 2004, Cristovam Buarque é exonerado por Lula e Tarso Genro é escolhido. Este nomeou Fernando Haddad para a Secretaria Executiva do Ministério. As principais iniciativas do que foi realizado em sua gestão são idealizadas e/ou lideradas por aquele. Por isso, a passagem de uma gestão a outra não apresentou solução de continuidade e serão tratadas aqui conjuntamente.

Estas gestões parecem retomar o programa de governo do PT, pelo menos como uma agenda para as ações, uma vez que a quase totalidade das propostas deste são retomadas e desenvolvidas por meio de programas e políticas posteriormente adotadas. 
Durante a gestão de Tarso Genro, as principais iniciativas do Ministério da Educação para o Ensino Superior estão concentradas em três áreas. A apresentação ao Congresso Nacional de um projeto de reforma universitária, a formulação de um novo modelo de avaliação em substituição ao Provão (SINAES) e um modelo de inclusão de estudantes oriundos das camadas mais pobres da população em instituições do setor privado (ProUni).

\section{A reforma que não houve: Reforma Universitária}

${ }^{6}$ Em 2009, Fernando Haddad defendeu a atualização do projeto, afirmando que este se tornara obsoleto.

\footnotetext{
${ }^{7}$ Uma boa discussão sobre o tema e a trajetória da reforma universitária, a partir do governo FHC até 2006, encontra-se em Sguissardi (2005) e Silva Junior e Sguissardi (2005).
}

O tema da reforma é interessante por duas razões principais. De certo modo, o texto apresentado ao Congresso Nacional, cristaliza aquilo que se tornou o projeto possível do governo Lula para a questão universitária, uma vez que ele foi longamente discutido e negociado com agentes políticos e com a sociedade civil. Nesse sentido, merece uma análise para quem estuda o governo do PT. Por outro lado, entretanto, como sua votação ficou para as calendas, denota também como ele era prescindível. Tanto para o governo como para o sistema. $\mathrm{O}$ enfrentamento, ou não, das questões implicadas aí se deu de forma diversa ${ }^{6}$.

O tema da reforma universitária estava na pauta do Ministério da Educação desde o governo FHC. No início do governo Lula, a necessidade de uma lei geral que regulasse o sistema federal de educação superior foi reposta. Havia questões consideradas fundamentais para o desenvolvimento do sistema que precisariam de uma regulação. Uma das principais era a autonomia universitária, assegurada pela Constituição de 1988, mas jamais regulamentada. Outra seria uma política mais estável para o setor privado e que pudesse oferecer um enquadramento para o emaranhado legal que se formara nos últimos anos. A discussão tomou um ano e meio e mobilizou cerca de duas centenas de organizações e atores sociais e foram apresentadas quatro versões de projetos de lei, sendo que a última, entregue em 2006 ao Congresso Nacional, nunca foi votada $^{7}$.

Na exposição de motivos assinada pelos ministros Fernando Haddad, Guido Mantega (Fazenda), Sergio Machado Rezende (Ciência e Tecnologia) e Paulo Bernardo Silva (Planejamento, Orçamento e Gestão), demonstrando a articulação interna da proposta, afirma-se que:

"São três os principais eixos normativos do Projeto de Lei em questão: (i)
constituir um sólido marco regulatório para a educação superior no País; (ii)
assegurar a autonomia universitária prevista no art. 207 da Constituição, tanto
para o setor privado quanto para o setor público, preconizando um sistema de
financiamento consistente e responsável para o parque universitário federal; e
(iii) consolidar a responsabilidade social da educação superior, mediante princí-
pios normativos e assistência estudantil" (Brasil 2013).

Martins (2006) apresenta uma análise bastante positiva do projeto, ao afirmar que este mantém sintonia com algumas tendências do cenário internacional, tais como "a democratização do acesso ao Ensino Superior, diversificação acadêmica e institucional dos centros de ensino, ampliação das funções do Ensino Superior, busca de uma maior pertinência social da atividade acadêmica etc" (idem, p.1015) Além disso, ele procuraria estabelecer um marco regulatório para assegurar a qualidade acadêmica das instituições.

"De forma adequada, distancia-se de certas sugestões formuladas por organismos multilaterais, tais com a desregulamentação do Ensino Superior, transferência de fundos públicos da educação superior para outros níveis de ensino, diminuição da participação estatal no financiamento das universidades públicas etc. O projeto contém pontos relevantes na recuperação da dimensão estratégica da educação superior, no processo de modernização e democratização do país, da retomada de sua dimensão pública. Ao mesmo tempo, aponta para o fortalecimento do ensino público, apresenta avanços significativos quanto à recom- 
posição da universidade federal, especialmente quanto ao seu financiamento" (Martins 2006, p.1010).

Sguissardi (2005, p.1047), por outro lado, critica duramente o projeto. O autor chama atenção para o fato de que salvaguardas existentes das primeiras versões foram abandonadas na última, que teria passado pelo crivo do Ministério da Fazenda. Além disso, aponta para questões como o silêncio sobre o percentual de investimento do PIB nas IFES, apesar da necessidade de ampliação da cobertura da população atendida, tendo em vista a meta do PNE, a manutenção das fundações de apoio nas universidades públicas com um perfil privatizante, a incipiente política de avaliação da qualidade nas instituições privadas e a igual validade de diplomas concedidos por universidades e faculdades, apesar das exigências díspares entre umas e outras.

Ao que parece, uma parte importante do esforço do projeto está centrado em oferecer um enquadramento legal consolidado para situações e/ou procedimentos já existentes de fato mas amparados tão somente em decretos, resoluções ou portarias. Ou ainda simplesmente ocupar um vácuo legal até então existente, como o caso da limitação de participação de capital estrangeiro em IES privadas.

Ou seja, há bem poucas inovações no projeto apresentado, o que talvez explique o pouco interesse que ele despertou no Congresso Nacional. É o caso, por exemplo, das exigências e prerrogativas conferidas às universidades, centros universitários e faculdades, que vão ao encontro do estabelecido no Decreto-Ponte n. 5.773 de 2006 e pelas demais resoluções e portarias emanadas logo no início da gestão de Haddad.

É interessante notar inclusive que a ausência da lei não causou nenhum embaraço nem para o setor público nem para o privado e, por isso, nenhum ator político importante manteve a luta por sua aprovação. O setor público, representado pelas universidades federais, expandiu-se como nunca antes e o setor privado manteve sua curva ascendente de crescimento, ainda que em menor velocidade. Para este último, apenas dois pontos que deixaram de ser normatizados poderiam ter potencialmente impacto sobre a dinâmica do setor. O primeiro é a exigência de que $70 \%$ do capital votante das mantenedoras estejam nas mãos de brasileiros natos ou naturalizados, tendo-se em vista o processo de internacionalização do setor, com a abertura de sociedades anônimas com participações de fundos de investimento estrangeiros. O outro é a composição majoritária de professores na composição dos colegiados superiores em universidades e centros universitários, numa tentativa de equilibrar o poder entre mantidas e mantenedoras. Mas, dificilmente ambas as exigências não seriam contornadas com os malabarismos administrativos para os quais o setor já tem traquejo.

Assim, apesar da amplitude do debate ocorrido e do forte engajamento dos diferentes atores, inclusive dos representantes do setor privado que chegaram a entregar uma versão própria de projeto de reforma ${ }^{8}$, a tramitação no Congresso Nacional esvaziou o tema e ele foi abandonado por todos.

\section{A política de avalição da educação superior: o SINAES}

8 Ver Associação Brasileira de Mantenedoras de Ensino Superior (2005).
O tema da avaliação da educação superior esteve na agenda da oposição ao governo de FHC desde a criação do Provão. As críticas mais comuns diziam respeito à simplificação conceitual embutida na ideia de reduzir a avaliação do sistema a uma prova realizada pelos alunos ao final do curso de graduação. Por isso, uma das primeiras iniciativas do ministro Tarso Genro foi a aprovação da lei do SINAES (Sistema Nacional de Avaliação da Educação Superior). Esta prevê que a avaliação esteja fundada no tripé constitutivo do Ensino Superior, 
9 A aplicação do ENADE passou por algumas mudanças nos últimos anos. Iniciou-se como amostral e passou a censitário. Em 2010, deixou de ser aplicado aos ingressantes, sendo substituído, para fins de cálculo do IDD, pelo desempenho do aluno no ENEM.

\footnotetext{
${ }^{10}$ Os mesmos autores apontaram para o desvirtuamento do espírito da lei ocorrido ao longo de sua implementação e a restauração dos rankings como um dos instrumentos principais da efetividade desta, deixando de lado a avaliação processual, formativa, democrática e emancipatória.
}

ou seja, o aluno, o curso e a instituição. Para cada ponta, procedimentos avaliativos distintos em termos de instrumentos utilizados e temporalidade de aplicação.

\author{
Segundo Barreyros e Rothen (2006, p.971):
}

"O SINAES é o resultado da cumulação e da metamorfose. Os três pilares que constituem o Sistema atualmente são derivados das experiências anteriores: a) a Avaliação Institucional, do PAIUB, b) a Avaliação dos Cursos de Graduação, da Avaliação das Condições de Ensino e c) o Exame Nacional do Desempenho dos Estudantes, do Provão. A cumulação dos mecanismos de avaliação foi realizada sem considerar que cada um deles é produto de valores e paradigmas divergentes: a visão formativa/emancipatória do PAIUB, fundada na participação e na autonomia institucional, a visão somativa da Avaliação das Condições de Ensino e o mecanismo de ranking do Provão".

Os alunos seriam submetidos ao ENADE (Exame Nacional de Cursos), que se constituía numa prova realizada no primeiro ano do curso e outra no último ano deste, expressando uma tentativa de medir não apenas o nível de conhecimento adquirido pelo estudante (produto), mas também o nível de aporte que a passagem pela instituição propicia a este (processo). A partir dessas duas notas, submetidas a ponderações estatísticas, o ENADE gera um conceito para cada curso envolvido. Além disso, com a criação posterior do IDD (Índice de Diferença entre o Resultado Esperado e o Observado), buscou-se realizar um ajuste mais fino no instrumento, de modo a conhecer melhor o sistema e não punir injustamente instituições que recebem alunos pouco qualificados, uma vez que estas seriam comparadas entre si. Durante o processo de implementação e modificação do SINAES, o IDD passou a ter importância crescente no processo de regulação, superando inclusive o conceito ENADE ${ }^{9}$.

A avaliação do curso se dá por duas variáveis: o desempenho de seus alunos no ENADE, ao qual é atribuído um conceito, e por uma visita in loco realizada por uma comissão ad hoc de especialistas. Esta avalia infraestrutura (instalações, laboratórios e biblioteca), qualificação e regime de trabalho do corpo docente e organização didático-pedagógica, que inclui a avaliação do projeto do curso e as condições de funcionamento operacional a ele oferecidas pela instituição, como a titulação e experiência do coordenador, a realização de eventos extracurriculares etc.

A última perna do tripé é a avaliação de cada instituição. Esta é realizada internamente a partir da criação de uma CPA (Comissão Própria de Avaliação) e no momento do seu recredenciamento, também realizada por uma comissão ad hoc de especialistas, por meio de uma visita que tem o intuito de identificar o perfil institucional e a qualidade de sua atuação, considerando inserção regional, atividades, cursos, programas, projetos e setores etc.

Segundo autores como Barreyro e Rothen (2009) e Dias Sobrinho (2008), o SINAES representava uma mudança substancial na concepção de avaliação, pois teria como centro o desenvolvimento institucional por meio de um ciclo avaliativo e instrumentos de auto avaliação ${ }^{10}$.

O conjunto de avaliações que compõe o SINAES tornou-se expressamente o referencial básico para os processos de regulação e supervisão da educação superior, para fins de emissão dos atos regulatórios de autorização, reconhecimento e renovação de reconhecimento de cursos e credenciamento e recredenciamento de instituições de educação superior.

A operação desse complexo sistema cabe à CONAES (Comissão Nacional de Avaliação do Ensino Superior) e ao INEP (Instituto Nacional de Pesquisas Educacionais Anísio Teixeira). A CONAES tem função consultiva para as diretrizes da política de avaliação e ao INEP cabe a elaboração dos instrumentos 
11 O Conceito Preliminar de Cursos (CPC) é composto de alguns índices, calculados a partir de pesos diferenciados, a saber: (a) desempenho dos concluintes no ENADE; (b) desempenho dos ingressantes no ENADE; (c) diferença entre os desempenhos esperados e observados; (d) titulação e regime de trabalho do corpo docente; (e) infraestrutura escolar e organização didático-pedagógica.

12 É um indicador de qualidade de instituições de educação superior que considera, em sua composição, a qualidade dos cursos de graduação e de pós-graduação (mestrado e doutorado). No que se refere à graduação, é utilizado o CPC (Conceito Preliminar de Curso) e, em relação à pós-graduação, é usada a nota Capes. O resultado está em valores contínuos (que vão de 0 a 500) e em faixas (de 1 a 5 ).

\footnotetext{
13 Para alguns autores, o governo Lula no seu segundo mandato adotou ou reeditou práticas do governo anterior: "ranking e mídia" (Barreyro \& Rothen 2009, p.1), retomando medidas próprias do paradigma técnico-burocrático (Dias Sobrinho 2008).
}

e a realização de todas as avaliações, além de realizar anualmente o Censo da Educação Superior.

A partir de 2008 foram criados novos índices que, na prática, passaram a ocupar uma parte do sistema avaliativo e mesmo substituí-lo. É o caso do Conceito Preliminar de Cursos (CPC) ${ }^{11}$ e do Índice Geral de Cursos (IGC) ${ }^{12}$. Estes índices facilitaram a reinstauração dos rankings entre as instituições, prática comum quando o Provão (1996-2003) era aplicado. Segundo Calderón, Poltronieri e Borges (2011), a importância dos rankings se tornou tamanha como estímulo à concorrência para a melhoria da qualidade da educação superior que teriam ganhado consenso e legitimidade públicas, deixando inclusive de serem políticas cambiantes de governo "para se tornarem política do Estado Brasileiro com vigência de longo prazo, acima dos interesses dos grupos políticos que se alternam no poder" (idem, p.820).

Esse fenômeno pode ser constatado pelo fato de que a elaboração e divulgação de rankings (hierarquizando os melhores e os piores cursos de graduação) passaram a ser feitos pelo próprio Ministério da Educação, que divulga os resultados em planilhas de Excel nas quais as notas das instituições aparecem em ordem decrescente.

Segundo Calderón, Poltronieri e Borges (idem), ocorre então algo semelhante ao que ocorreu na era FHC: a sobreposição e a primazia de um instrumento de avaliação sobre os demais.

\begin{abstract}
“Naquele governo, o 'Provão' ganhava a mídia e ficavam no ostracismo os outros instrumentos: Avaliação das Condições de Ensino (ACE) e a Avaliação Institucional. $\mathrm{O}$ fenômeno se repete no segundo mandato do governo Lula. $\mathrm{O}$ Enade ganha a mídia, enquanto a Avaliação Institucional e, principalmente, a Autoavaliação ficaram no ostracismo. Desta forma, o Provão e o Enade, que têm na sua essência a elaboração de rankings se constituem nos instrumentos indutores da qualidade por meio da concorrência, dinamizando o mercado educacional" (idem, p.817)
\end{abstract}

Isso pode ser verdade, mas é preciso considerar que há uma diferença importante entre as políticas adotadas pelos respectivos governos. Pois enquanto no governo FHC a divulgação da avaliação se constituía como a única "medida" tomada pelo governo em relação às instituições e aos cursos considerados deficientes a partir da avaliação, uma vez que expunha essa deficiência aos olhos da opinião pública, no governo Lula, pela primeira vez, foram realizadas ações efetivas de supervisão e punição por parte do MEC. Ou seja, o governo não deixou apenas ao mercado e aos consumidores a decisão sobre a continuidade ou o crescimento das instituições do sistema ${ }^{13}$.

As ações de supervisão e punição foram possíveis a partir da promulgação do Decreto n. 5.773, de 9 de maio de 2006, depois de ter sido colocado à discussão pública durante o mês de fevereiro do mesmo ano, já na gestão de Fernando Haddad como ministro. Foi chamado pelo próprio Ministério da Educação de decreto ponte, e fez parte da "faxina legislativa", empreendida pelo novo ministro. Ponte até a aprovação da reforma universitária, da qual adianta alguns pontos. Ele substituiu o Decreto n. 3.860/2001, que dispunha sobre a organização do Ensino Superior e regulamentava a Lei n. 9.131/95 nos aspectos relativos aos procedimentos da avaliação.

Segundo Barreyros e Rothen (2006, p.970):

"Na sua estruturação, o decreto assume a tese defendida pela Comissão Especial de Avaliação na sua proposta, retomada na orientação das Diretrizes para a Avaliação das Instituições de Educação Superior, de que a regulação/avaliação ocorre em três momentos distintos: a) a regulação pelo poder público nas etapas iniciais da autorização e credenciamento; b) a avaliação e c) a aplicação pelo poder público dos efeitos regulatórios da avaliação". 
Durante o governo Lula, foi realizada uma grande investida de ações de supervisão nos cursos superiores de Direito e na educação a distância. Segundo dados oficiais, até março de 2010, 89 cursos passaram pela supervisão e cerca de 20.000 vagas foram suspensas. Dois cursos foram fechados (MEC 2010). No caso da educação a distância, os números da supervisão, segundo dados de 2010 são exibidos na Tabela 1 .

Uma medida acessória mas importante para a política de avaliação do Ensino Superior foi a reformulação do Censo. Apesar de ser realizado com alguma regularidade desde 1930, apenas em 2008, por meio do Decreto $\mathrm{n}^{\circ} 6.425$, ele se torna obrigatório. A partir de reformulações recentes, o Censo da Educação Superior levanta, por meio eletrônico, informações individualizadas sobre instituições, cursos, alunos e docentes, vagas, candidatos, ingressantes, matrícula, concluintes, docentes e extensão universitária. É realizado em parceria com as instituições de Ensino Superior, que alimentam anualmente o banco de dados em período pré-determinados. Os dados do censo potencialmente aumentam o controle sobre as instituições de Ensino Superior nos processos avaliativos, uma vez que permitem o cruzamento de informações indispensáveis a estes, como por exemplo, a titulação e o regime de trabalho de professores efetivamente vinculados a um determinado curso. Além disso, subsidiam o cálculo do Conceito Preliminar de Curso (CPC) e Índice Geral Curso (IGC).

Segundo dados oficiais, entre 2004 e 2009, foram realizadas 14.270 avaliações in loco de instituições de educação superior (IES) e de cursos de graduação. Considerando aquilo que a nova legislação chama de atos de regulação e supervisão, são 15.312 atos de credenciamento, recredenciamento e descredenciamento de instituições, autorização, reconhecimento, renovação de reconhecimento e desativação de cursos.

O ENADE foi aplicado até 2008, de forma amostral, aos estudantes nas áreas avaliadas anualmente e, a partir de 2009, passou a ser adotado para todos os estudantes ingressantes e concluintes, ampliando significativamente a participação na avaliação da educação superior. Em 2004, o Exame foi efetivamente aplicado a 140.340 estudantes e, em 2009, no formato censitário, foi feito por 802.534 estudantes. Em 2010, o ENADE foi realizado em 1.344 municípios, sendo disponibilizado pela primeira vez nos polos de educação a distância ${ }^{14}$.

\section{O Programa Universidade para Todos: política redistributiva?}

${ }^{14}$ Ver Brasil (2010a).

O ProUni foi uma das politicas mais polêmicas e populares do governo Lula. Pretendia de uma só vez atacar dois problemas estruturais do sistema de Ensino

Tabela 1 - Balanço das ações de supervisão na EAD

\begin{tabular}{lc}
\hline Tipo & Quantidade \\
\hline Instituições em supervisão & 38 \\
Termos de saneamento assinados & 12 \\
Descredenciamentos & 1 \\
Processos administrativos para descredenciamento & 2 \\
Polos de apoio presencial fechados & 3.800 \\
Número de ingressos suspensos & Mais de 20.000 \\
\hline
\end{tabular}

Nota: O descredenciamento foi o da Universidade de Tocantins (Unitins), ocorrido em 2009. Ver Brasil (2009).

Fonte: A autora, a partir de Brasil (2010). 
${ }^{15}$ Cf. Carvalho (2006). Segundo o Censo 2010, a taxa líquida de escolarização ao final do governo Lula atingiu $14,4 \%$.
${ }^{16}$ Não foi possível confirmar que as filantrópicas e comunitárias sem fins lucrativos responderiam de fato por $85 \%$ das vagas no setor privado na ocasião da aprovação do ProUni,
Superior. De um lado, a barreira socioeconômica que praticamente interditava a inclusão das camadas mais desfavorecidas no sistema, de outro o problema do enquadramento fiscal das instituições filantrópicas e sem fins lucrativos.

Em primeiro lugar, é preciso lembrar que, malgrado toda expansão havida durante o governo FHC, em 2004 a escolaridade líquida da população de 18 a 24 anos ainda era de apenas de 10,4\%, sistema classificado internacionalmente como de elite ${ }^{15}$. Para compreender a dimensão desse elitismo, precisamos desagregar os dados por renda familiar per capita em salários mínimos nessa faixa etária. Segundo Carvalho (2006, p.992) “observa-se que a proporção de alunos aumenta conforme as faixas de renda mais elevadas. Nas faixas acima de três salários mínimos, a proporção de estudantes é superior a 35\%, ao passo que, com a renda de até um salário mínimo, apenas 1,5\% frequenta a graduação". Segundo a mesma autora, utilizando dados de Castro (2005), 86\% da população na faixa etária 18-24 anos enquadra-se nos níveis de renda de menos de três salários mínimos, público-alvo do ProUni.

\begin{abstract}
"A situação é mais grave, pois a maior parte dessa população encontra- se em atraso escolar e, dessa forma, não pode ser atingida por qualquer política de estímulo à entrada no sistema. De acordo com os dados da PNAD (1999): 46\% abandonaram os estudos antes de completar o ensino médio; $10 \%$ estudam, mas com distorção de idade-série; $19 \%$ terminaram o ensino médio e pararam de estudar; e apenas $25 \%$ frequentam o ensino médio ou superior" (Carvalho 2006, p.993)
\end{abstract}

Neste contexto não é de se admirar que o programa tenha tido o apoio de parte significativa da sociedade civil, de sindicatos e do movimento estudantil e dos movimentos sociais em prol das ações afirmativas, "bem como dos egressos do ensino médio público, por não se considerarem uma demanda potencial às instituições públicas frente às barreiras impostas pelos exames vestibulares" (idem, p.985).

O segundo problema a ser enfrentado pelo programa, o das entidades filantrópicas, é assim descrito em uma publicação do MEC de 2008 intitulada Revista do ProUni, concebida para divulgar os números e pretensos benefícios sociais do programa:

"Com atraso de 16 anos, foram reguladas pelo ProUni as isenções fiscais constitucionais concedidas às instituições privadas de Ensino Superior. De 1988 a 2004, as instituições de Ensino Superior sem fins lucrativos, que respondem por $85 \%$ das matrículas do setor privado, amparadas pela Constituição Federal, gozaram de isenções fiscais sem nenhuma regulação do Poder Público. Ou seja, sem nenhuma contrapartida. Acórdão do Supremo Tribunal Federal (STF), de 1991, tornou reconhecida a lacuna legislativa. Mas, por conta dessa omissão, garantia o gozo das isenções enquanto perdurasse a situação" (Brasil 2008, p.6) ${ }^{16}$.

Segundo a publicação, até 2004 as instituições sem fins lucrativos concediam bolsas de estudos, "mas eram elas que definiam os beneficiários, os cursos, o número de bolsas e os descontos concedidos" (ibidem). Como resultado, raramente era concedida uma bolsa integral e quase nunca em curso de alta demanda e alto custo como Medicina e Engenharia. Desse modo, a isenção fiscal, já existente, não resultaria em uma ampliação do acesso ao Ensino Superior, além de ser discricionária. O ProUni, por outro lado, ao regulamentar a situação, estabelece que as instituições beneficiadas por isenções fiscais passem a conceder bolsas de estudos na proporção dos alunos pagantes por curso e turno, sem exceção.

É preciso lembrar, conforme Carvalho (2006), que o Estado brasileiro lança mão de política de incentivos e isenções fiscais para apoiar a atuação privada 
17 Para uma boa análise da transformação da proposta inicial do governo e do processo de implantação inicial do PROUNI, ver Catani, Hey \& Gilioli (2006).

18 Um dos últimos atos do ministro Fernando Haddad, já no governo Dilma Rousseff, foi a comemoração pelas um desde o final dos anos de 1960, quando o governo militar valeu-se desses instrumentos para impulsionar o projeto de desenvolvimento nacional, beneficiando ampla gama de setores em diferentes áreas. Segundo a autora:

"Em relação ao Ensino Superior, o mecanismo de renúncia fiscal tornou-se fator central no financiamento do segmento privado. A Lei n. 5.172/66, que instituiu o Código Tributário Nacional, em concordância com a CF/67, determinava a não incidência de impostos sobre a renda, o patrimônio e os serviços dos estabelecimentos de ensino de qualquer natureza. Em outras palavras, as organizações privadas de Ensino Superior gozaram do privilégio, desde a sua criação, de imunidade fiscal, não recolhendo aos cofres públicos a receita tributária devida. [...] Apesar de existirem requisitos restritivos para as entidades educacionais terem acesso à imunidade fiscal, na prática, grande parte usufruiu deste benefício" (idem, p.982).

A ideia da troca de bolsas de estudos para alunos carentes por isenções fiscais já havia sido cogitada desde os anos de 1990, sem sucesso. Segundo Gilda Gouvea, então assessora do ministro Paulo Renato, a ideia chegou a ser apresentada a ele, que teria avaliado que não havia condições políticas para tal. Tão logo chegou ao ministério, Fernando Haddad a retomou e obteve a pronta aprovação do presidente Lula. A negociação com os representantes do setor privado e posteriormente com o Congresso Nacional foi difícil e tortuosa. $\mathrm{O}$ projeto original sofreu inúmeras alterações antes de ser aprovado ${ }^{17}$, inclusive quanto aos percentuais de desconto concedido aos alunos e ao número total de bolsas exigidas das instituições, que chegou à metade do proposto inicialmente no PL.

O presidente Lula parecia ter pressa na adoção do programa porque apesar de ter enviado ao Congresso um projeto de lei, logo depois editou, em 10 de setembro de 2004, a Medida Provisória (MP) no 213, que instituiu o Programa Universidade para Todos. Logo em seguida, o Decreto $\mathrm{n}^{\circ} 5.245$, de 18 de outubro de 2004, regulamentou a MP e a Portaria no 3.268 , de 19 de outubro de 2004, estabeleceu os procedimentos para adesão das instituições privadas de educação superior ao ProUni. Mais recentemente, em 13 de janeiro de 2005, o Programa foi transformado em lei - Lei $\mathrm{n}^{\mathrm{o}}$ 11.096/05.

O ProUni concede a todas as instituições privadas (com ou sem fins lucrativos) que aderem ao programa isenção de Imposto de Renda de Pessoa Jurídica, Contribuição Social sobre o Lucro Líquido, Contribuição Social para Financiamento da Seguridade Social e Contribuição para o Programa de Integração Social. O aluno precisa comprovar sua condição socioeconômica e sua qualificação acadêmica e/ou profissional, atendendo alguns pré-requisitos: obter nota mínima de 450 pontos no ENEM; ter renda familiar, por pessoa, de até três salários mínimos, ter cursado o Ensino Médio completo em escola pública, ou o Ensino Médio completo em escola privada com bolsa integral, ou ser portador de deficiência, ou, ainda, ser professor da rede pública de Ensino Básico, em efetivo exercício, concorrendo a vagas em cursos de Licenciatura ou Pedagogia, sendo que, neste caso, a renda familiar por pessoa não é considerada.

Ao final do governo Lula, segundo balanço oficial, foram contabilizados 748 mil estudantes com bolsas do ProUni, sendo 69\% com bolsas integrais. Desse total, $48 \%$ são afrodescendentes. Dentre estes, 5.194 estudantes receberam bolsa permanência, no valor de $\mathrm{R} \$ 300,00$, destinada a alunos que realizam cursos de período integral (mais de seis horas diárias). Os dados de 2010 indicavam que havia 462 mil bolsas em utilização e 116 mil estudantes com a graduação concluída como bolsistas do ProUni (Tabela 2) ${ }^{18}$.

As críticas recebidas pelo programa foram variadas e compreendem diferentes vertentes. As mais comuns referem-se à transferência de recursos públi- 
milhão de bolsas concedidas, no início de 2012. Ver Brasil (2012).

\footnotetext{
19 O ProUni é controlado, em âmbito nacional, pela Comissão Nacional de Acompanhamento e Controle Social do ProUni (Conap) e, em âmbito regional, pelas comissões locais de acompanhamento e controle social, presentes onde cada instituição oferta seus cursos. Ver Brasil (2010a).

${ }^{20}$ Uma crítica mais recente refere-se à concentração das vagas ofertadas no Sul e Sudeste, uma vez que estas são as regiões onde o setor privado é mais atuante.
}

Tabela 2 - Número de bolsas ocupadas no ProUni (2005-2010)

\begin{tabular}{lc}
\hline Ano & Bolsas ocupadas \\
\hline 2005 & 95.608 \\
2006 & 204.625 \\
2007 & 310.186 \\
2008 & 434.750 \\
2009 & 596.077 \\
2010 & 748.788 \\
\hline
\end{tabular}

Fonte: A autora, a partir de Brasil (2010a).

cos (impostos devidos) ao setor privado, incentivando a privatização do sistema de Ensino Superior, à falta de controle público sobre a qualidade das instituições participantes e as bolsas concedidas ${ }^{19}$, ao reforço da política discriminatória, que relega uma educação de baixa qualidade (privada) para a população mais carente, à precariedade das políticas de manutenção no sistema do estudante atendido ${ }^{20}$.

\section{Segundo Mancebo (2004b, p.13):}

“[...] longe de resolver ou de corrigir a distribuição desigual dos bens educacionais, a privatização promovida pelo programa tende a aprofundar as condições históricas de discriminação e de negação do direito à educação superior a que são submetidos os setores populares. A alocação dos estudantes pobres nas instituições particulares cristalizará mais ainda a dinâmica de segmentação e diferenciação no sistema escolar, destinando escolas academicamente superiores para os que passarem nos vestibulares das instituições públicas".

É preciso considerar, entretanto, que mecanismos de renúncia fiscal têm sido utilizados pelo Estado brasileiro desde muitas décadas, em diferentes contextos. A partir de 2008, por exemplo, foi largamente utilizado como instrumento da política econômica anticrise. A renúncia ao IPI dos automóveis, um exemplo comum, beneficia tanto a indústria automobilística e toda a sua cadeia produtiva quanto os consumidores das classes média e alta, que podem adquirir um carro. Nesse sentido, o ProUni pode ser visto como uma política de redistribuição indireta de renda, na medida em que beneficia os estratos mais pobres. A maior parte dos alunos beneficiados se encontra estruturalmente excluída da rede pública, se considerarmos que esta, além de seu tamanho diminuto, situa-se em grandes centros urbanos e oferece cerca de $70 \%$ de seus cursos em período diurno. De acordo com Corbucci, mesmo que os recursos renunciados "fossem arrecadados, não beneficiariam necessariamente esses grupos sociais" (Corbucci 2004, p.698).

Outra medida foi a reformulação do Fundo de Financiamento ao Estudante do Ensino Superior (FIES), criado ainda em 1999²1, em substituição ao antigo Programa de Crédito Educativo, herança do regime militar. As principais mudanças foram a disponibilização do FIES a fluxo contínuo, permitindo aos estudantes contratarem o financiamento a qualquer tempo do curso. A carência foi ampliada para 18 meses e o prazo para pagamento dilatado para três vezes o tempo de utilização do financiamento. Os juros para todos os contratos passaram para 3,4\% anuais e foi facultado aos estudantes dos cursos de Medicina e licenciaturas ressarcirem o financiamento com trabalho nas redes públicas de educação e saúde, amortizando $1 \%$ da dívida consolidada por mês de trabalho.

Foi lançado ainda o Fundo de Garantia de Operações de Crédito Educativo (FGEDUC), constituído com recursos do Tesouro Nacional e contribuições das entidades mantenedoras de instituições de Ensino Superior, com o objetivo de 
22 Ver, por exemplo, autores como Dourado (2009); Paula (2009); Gomes (2003); Sguissardi (2006), entre outros. prestar fiança aos estudantes matriculados em curso de licenciatura ou que possuam renda familiar mensal bruta per capita de até um salário mínimo e meio. Em 2010, até outubro, mais de 60 mil contratos foram firmados, no valor global superior a R\$ 2 bilhões (Brasil 2010a).

A literatura sobre as políticas adotadas pelo governo Lula é bastante severa. A esmagadora maioria dos intérpretes, apesar de reconhecer os avanços havidos em relação à ampliação do setor público, é crítica em relação à maneira como esta foi conduzida, apontando para a precariedade das novas universidades públicas e a manutenção da lógica privatizante nas políticas adotadas, tanto em relação ao setor privado quanto ao setor público, sendo que, para este último, as metas do REUNI seriam o exemplo mais evidente ${ }^{22}$.

Em relação ao setor privado, as expectativas de controle da expansão e da qualidade das instituições, principalmente quando da aprovação do SINAES, foram frustradas. Ainda que os números do crescimento do setor privado tenham sofrido significativa queda, este já é de tal monta e relevância que as iniciativas do governo pareceram tímidas e paliativas.

Além disso, a adoção do ProUni é vista como o recrudescimento da chamada lógica mercantilista-privatizante já presente no governo anterior. Minto (2011) aponta, por exemplo, que uma metamorfose ideológica-conceitual (transformando a educação de direito a bem público) permitiu ao governo Lula instituir os mecanismos do programa, uma vez que "o Estado garante a todos o consumo de um bem (equidade). Por isso não há impedimento para que as IES privadas recebam recursos estatais, já que se organizam para exercer uma função social de "interesse público"” (idem, p.260).

Nesse sentido, o autor defende a ideia de um "adensamento privatista" da educação superior.

"Adensamento, pois ele não inaugura a presença dos interesses privados no Ensino Superior, mas acarreta sua reestruturação, fazendo com que o adensamento seja, por um lado, absoluto (crescimento das IES privadas e de sua presença no campo da educação superior); e, por outro lado, relativo, também no interior das IES e nas suas formas de relação com a sociedade e o Estado" (idem, p.263).

Vemos então que o teor das críticas ao governo Lula, pelo menos no que tange às políticas adotadas para o setor privado, mantêm a discussão em torno dos temas da privatização do sistema. Aqui, ainda temos a decepção daqueles que esperavam uma mudança de rumo mais acentuada.

\section{Conclusões}

A análise das políticas adotadas pelo governo Lula indica que este privilegiou algumas questões da agenda da educação superior, como a ampliação e democratização de acesso, inclusive procurando o viés da equidade, ao contemplar populações historicamente não atendidas, quer por razões econômicas, quer, aliada a estas, raciais. Outra questão que mereceu destaque entre as políticas implementadas é a representada pelo par qualidade/massificação, uma vez que houve um razoável aperfeiçoamento dos instrumentos de avaliação, como garantidores da qualidade do sistema, ao lado de um grande incremento da educação a distância, com enfoque francamente massificador.

Considerando as questões relativas à mercantilização/privatização, os resultados foram mais controversos. Se, de um lado, a privatização sofreu um pequeno reflexo, principalmente por conta da ampliação das vagas em instituições federais, por outro, a mercantilização se aprofundou. A ausência da regulamentação quanto à possibilidade de abertura de capital das mantenedoras 
e à atuação dos fundos de capital nacionais ou estrangeiros permitiu o surgimento de megagrupos financeiros que exploram a educação superior como uma commodity cuja principal função é gerar dividendos aos acionistas.

Vilma Aguiar (vilmaaguiar@gmail.com) é Doutora em Ciências Sociais pela Universidade Estadual de Campinas (Unicamp) e membro do Núcleo de Pesquisa das Interações Estado/Sociedade da Universidade Federal do Paraná (UFPR). Vínculo Institucional: Universidade Federal do Paraná, Curitiba, PR, Brasil.

\section{Referências}

Aguiar, V., 2013. Ampliação e diversificação do acesso no Ensino Superior: a formação do sistema de massa no setor privado. Tese de Doutorado. Campinas: Universidade Estadual de Campinas.

Barreyro, G.B. \& Rothen, J., 2006. "SINAES” Contraditórios: considerações sobre a elaboração e implementação do Sistema de Nacional de Avaliação do Ensino Superior. Educação \& Sociedade, 27, pp.955-977. DOI: 10.1590/s0101-73302006000300015

Brunner, J.J. \& Uribe, D., 2007. Mercados universitários: el nuevo scenario de la educación superior. Santiago: Ediciones Universidad Diego Portales.

Calderón, A.I.; Poltronieri, H. \& Borges, R.M., 2011. Os rankings na educação brasileira: políticas de Estado ou de governo? Ensaio: Avaliação e Políticas Públicas em Educação, 19(73), pp.813-826.

Carvalho, C.A., 2006. O PROUNI no governo Lula e o jogo político em torno o acesso ao Ensino Superior. Educação \& Sociedade, 27(96), pp.979-1000. DOI: 10.1590/s0101-73302006000300016

Castro, M.H.G. et al., 2005. Ensino superior: perfil da graduação e da pós-graduação. In F.R. Landi, ed. Indicadores de ciência, tecnologia e inovação em São Paulo: 2004. São Paulo: FAPESP.

Catani, A.M.; Hey, A.P. \& Gilioli, R.S.P., 2006. ProUni: Democratização do acesso às instituições de Ensino Superior? Educar em Revista, 28(6), pp.125-140. DOI: 10.1590/s0104-40602006000200009

Corbucci, P.R., 2004. Financiamento e democratização do acesso à educação superior no Brasil: da deserção do Estado ao projeto de reforma. Educação \& Sociedade, 25(88), pp.677-701. DOI: 10.1590/s0101-73302004000300003

Dias Sobrinho, J., 2010. Democratização, qualidade e crise da educação superior: faces da exclusão e limites da inclusão. Educação \& Sociedade, 31(113), pp.1223-1245. DOI: 10.1590/s0101-73302010000400010

Dourado, L.F., 2008. Políticas e gestão da educação superior a distância: novos marcos regulatórios? Educação \& Sociedade, 29(104), pp.891-917. DOI: 10.1590/s0101-73302008000300012

Gomes, A.M., 2003. Estado, mercado e educação superior no Brasil: um modelo analítico. Educação \& Sociedade, 24(84), pp.839-872. DOI: 10.1590/s0101-73302003000300006

Mancebo, D., 2004. "Universidade para todos": a privatização em questão. Pro-Posições, 15(3), pp.75-90.

Martins, C.B., 2006. Uma reforma necessária. Educação \& Sociedade, 27(96), p.1001-1020. DOI: 10.1590/S010173302006000300017

Minto, L.W., 2011. A educação da "miséria": particularidade capitalista e educação superior no Brasil. Tese de Doutorado. Campinas: Universidade Estadual de Campinas.

Morosini, M.C., 2009. Qualidade na educação superior: tendências do século. Estudos em Avaliação Educacional, 20(43), pp.165-186. DOI: 10.18222/eae204320092043

Otranto, C.R., 2006. Desvendando a política da educação superior do governo lula. Universidade \& Sociedade, XVI(38), pp.18-29.

Paula, M.F., 2009. Reforma da educação superior do Governo Lula: as políticas de democratização do acesso em foco. Revista Argentina de Educacion Superior, 1(1), pp.152-172.

Pereira, T.I. \& Silva, L.F.S.C., 2010. As políticas públicas do Ensino superior no governo Lula: expansão ou democratização? Revista Debates, 4(2), pp.10-31.

Sampaio, H., 2000. O Ensino Superior no Brasil: o setor privado. São Paulo: Hucitec.

2014. Diversidade e diferenciação no ensino superior no Brasil: conceitos para discussão. Revista Brasileira de Ciências Sociais, 29(84), pp.43-55. DOI: 10.1590/s0102-69092014000100003

Sguissardi, V., 2005. Universidade pública estatal: entre o público e o privado/mercantil. Educação \& Sociedade, 26(90), pp.191-222. DOI: 10.1590/s0101-73302005000100009

2006. Reforma Universitária no Brasil - 1995-2006: Precária trajetória e incerto futuro. Educação \& Sociedade, 27(96), pp.1021-1056. DOI: 10.1590/s0101-73302006000300018

Silva Junior J.R. \& Sguissardi, V., 2005. A nova lei de educação superior: fortalecimento do setor público e regulação do privado/mercantil ou continuidade da privatização e mercantilização do público? Revista Brasileira de Educação, 29, pp.5-27. DOI: $10.1590 / \mathrm{s} 1413-24782005000200002$

Souza, C., 2006. Políticas Públicas, uma revisão da literatura. Sociologias, 8(16), pp.20-45. DOI: 10.1590/s151745222006000200003

Viana, A.L., 1996. Abordagens metodológicas em políticas públicas. Revista de Administração Pública, 30(2), pp.5-43. 


\title{
Outras fontes
}

Associação Brasileira de Mantenedoras de Ensino Superior, 2005. ABMES Cadernos, 15. Disponível em: http://www.abmes.org.br/abmes/public/arquivos/publicacoes/Cadernos15.pdf. Acesso em: 17 fev 2016.

Brasil, 2001. Financiamento ao Estudante do Ensino Superior (FIES) e dá outras providências. Diário Oficial da União, 13 jul. (Alterada pela Lei n. 11.552, de 19 de novembro de 2007, publicada no Diário Oficial da União, em 31 maio 2007). 2005. Lei n. 11.096, de 13 de janeiro de 2005. Institui o Programa Universidade para Todos (PROUNI). Diário Oficial da União, 14 jan.

, Ministério da Educação, 2008. Palavra do ministro. Braília: MEC. Disponível em: http://prouniportal.mec.gov.br/images/pdf/Revista_ProUni/Revista_ProUni.pdf. Acesso em: 19 fev 2016.

Governo Federal, 2009. Diário Oficial da União, 15. Disponível em: http://www.cfess.org.br/arquivos/Portaria.pdf. Acesso em: 16 fev 2016.

. Governo Federal, 2010a. Balanço de governo 2003-2010. 3. Educação. Brasília: Governo Federal. Disponível em: https://i3gov.planejamento.gov.br/dadosgov/textos/livro3/3.2_Educacao.pdf. Acesso em: 17 fev 2016.

Ministério da Educação, 2010b. Censo da educação superior. Brasília: INEP. Disponível em: http://portal.inep.gov.br/web/censo-da-educacao-superior. Acesso em: 16 fev 2016.

. Presidência da República, 2012. Prouni já concedeu 1 milhão de bolsas de estudo em universidades particulares. Blog do Planalto, 13 jan. Disponível em: http://blog.planalto.gov.br/prouni-ja-concedeu-1-milhao-debolsas-de-estudo-em-universidades-particulares/. Acesso em: 16 fev 2016.

. Casa Civil, 2013. Plano de ação visando a reestruturação, desenvolvimento e democratização das Instituições Federais de Ensino Superior - IFES. Disponível em: http://www.sintunesp.org.br/refuniv/GTInterministerial\%20-\%20Estudo.htm. Acesso em 16 fev 2016.

\begin{abstract}
The paper presents and analyzes the key policies for the private sector of higher education adopted by the government of Luiz Inacio Lula da Silva (2003/ 2010). From a historical retrospective and an analysis of their implementation, policies are considered through a critical review of the literature and official data. The work seeks to demonstrate that, despite the quite distinct policies for the public sector if compared with the government of Fernando Henrique Cardoso, in the case of the private sector, there is rather a deepening of policy options already developed during the Cardoso government. These options translate into actions to encourage the development of the private sector, to the extent that the financing of this expanded and consolidated legal framework that provided legal certainty to sponsors. This promotion, however, was accompanied by a significant increase and improvement of the mechanisms of control over the growth of the private sector. The result was a fall in the growth of the private sector, even though it has remained at a fairly high level.
\end{abstract}

KEYWORDS: private sector of higher education; university reform; higher education; public policies; Lula government.

This is an Open Access article distributed under the terms of the Creative Commons Attribution Non-Commercial License which permits unrestricted non-commercial use, distribution, and reproduction in any medium provided the original work is properly cited. 